\title{
Differing deregulation of HER2 in primary gastric cancer and synchronous related metastatic lymph nodes
}

Mitsugu Kochi ${ }^{1}$, Masashi Fujii ${ }^{1}$, Shinobu Masuda ${ }^{2}$, Noriaki Kanamori ${ }^{1}$, Yoshiaki Mihara' ${ }^{1}$ Tomoya Funada ${ }^{1}$, Hidenori Tamegai ${ }^{1}$, Megumu Watanabe ${ }^{1}$, Hiroshi Suda ${ }^{1}$ and Tadatoshi Takayama ${ }^{1 *}$

\begin{abstract}
Background: The aim of this study was to investigate how differences in expression of HER2 between primary gastric cancers (PGCs) and their corresponding metastatic lymph nodes (LMNs) might affect its potential as a prognostic indicator in treatments including anti-HER2 agents.
\end{abstract}

Methods: The analysis was conducted in 102 patients who underwent surgical resection for primary gastric cancers (PGCs; adenocarcinoma, intestinal type) with synchronous LNMs. HER2 gene status and protein expression were investigated by immunohistochemistry $(\mathrm{IHC})$ in all patients; fluorescence in situ hybridization (FISH) was performed in 22 patients. The correlation between HER2 gene status in PGCs and their LNMs was evaluated.

Results: Positive HER2 expression as detected by IHC + FISH was observed in 27/102 PGC samples (26.5\%) and 29/102 LNM samples (28.4\%). HER2 amplification status in 102 paired PGC and LNM samples as evaluated by FISH + IHC was concordant in 92 patients (90.2\%), 69 (67.6\%) were unamplified and 23/102 (22.5\%) were amplified at both sites, and discordant in 10 patients (9.8\%), 4 (3.9\%) were positive for PGC and negative for LNM, while 6 (5.9\%) were positive for LNM and negative for PGC. The results of FISH + IHC showed very strong concordance in HER2 status between the PGC and LNM groups $(k=0.754)$.

Conclusion: The high concordance between HER2 results for PGCs and their LNMs indicates that assessment of HER2 status in the primary cancer alone is a reliable basis for deciding treatment with anti-HER2 agents in patients with LNMs from gastric adenocarcinoma.

Virtual slides: The virtual slide(s) for this article can be found here: http://www.diagnosticpathology.diagnomx.eu/vs/ 9365749431029643.

Keywords: Gastric cancer, HER2, Lymph node metastasis, Primary tumor

\section{Background}

A large number of studies have shown that HER2positivity, which is associated with poor prognosis, is detected in $7 \%$ to $34 \%$ of patients with gastric cancer [1-9]. Moreover, recent advances in technology have made detection of HER2 much easier, thus increasing its potential as a prognostic marker [10,11].

Currently, clinical trials of trastuzumab and lapatinib are being conducted based on the findings of earlier

\footnotetext{
* Correspondence: takayama.tadatoshi@nihon-u.ac.jp

1 Department of Digestive Surgery, Nihon University School of Medicine, 30-1OHyaguchi Kamimachi, Itabashi-ku, Tokyo 173-8610, Japan

Full list of author information is available at the end of the article
}

preclinical in vitro and in vivo studies demonstrating that they were effective in different gastric cancer models.

Trastuzumab, a monoclonal antibody against human epidermal growth factor receptor 2 (HER2; also known as ERBB2), in combination with chemotherapy is considered a new standard option in patients with HER2positive advanced gastric or gastro-esophageal junction cancer [12]. The efficacy of trastuzumab in metastatic gastric cancer may be influenced by downstream deregulation of HER2 signaling proteins detected in the primary tumor.

These earlier data were obtained by analyzing the clinical response in gastric cancer patients with regard to

\section{Biomed Central}


molecular features detected in the primary gastric cancers (PGCs). However, metastases may have molecular patterns which differ from those of the primary tumor, and this might affect how accurately we can predict the efficacy of HER2-targeted therapy. Differences in HER2 expression between primary tumors and their lymph node metastases (LMNs) could not explain the high proportion of non-responders to trastuzumab therapy in breast cancer [13-15]. However, the level of expression of a particular molecular marker or gene status may differ between a PGC and its corresponding metastatic lesions, and this may affect the clinical significance of predictive tests.

The purpose of the present study was to determine how differences in expression of HER2 between PGCs and their corresponding LMNs might affect its potential as a prognostic indicator in treatments including antiHER2 agents.

\section{Material and methods Patient population}

Between January 1990 and December 2010, 102 patients underwent gastrectomy for PGCs histopathologically classified as adenocarcinoma, intestinal type together with dissection of synchronous LNMs at the Department of Digestive Surgery, Nihon University School of Medicine Itabashi Hospital. The analysis was conducted in PGCs with synchronous LNMs. Tissue specimens were obtained from both the PGCs and their associated LNMs. All the specimens were fixed in $4 \%$ neutral buffered formalin and embedded in paraffin before being sent to a local pathology facility for evaluation. This study was approved by the Research review board, Nihon University School of Medicine, Itabashi Hospital (No RK-100910).

\section{Molecular analyses}

All the specimens obtained were reviewed for quality and tumor content. A single representative tumor specimen from each patient containing at least 70\% neoplastic cells was selected for immunohistochemical, cytogenetic, and molecular analyses. The tumor blocks were cut into $3-\mu \mathrm{m}$ thick sections for analysis by both fluorescence in situ hybridization (FISH) and immunohistochemistry (ICH).

\section{Assessment of HER2 status by IHC}

The tumors were centrally tested by ICH for HER2 status (HercepTest; Dako, Kyoto, Japan). HER2 immunoreactivity was evaluated by an experienced pathologist according to the scoring system of Hofmann et al. [16]. Samples exhibiting strong, complete, basolateral or lateral membranous reactivity (3+) in $\geq 10 \%$ of the cells were scored as positive. Samples with no reactivity or membranous reactivity in $<10 \%$ of the cells, or with only faint or barely perceptible membranous reactivity $(1+)$ in $\geq 10 \%$ of the tumor cells (cells showing reactivity in only one area of their membrane) were considered negative. Samples showing weak-to-moderate, complete, basolateral or lateral membranous reactivity $(+2)$ in $\geq 10 \%$ of the tumor cells were scored as equivocal. Patients were eligible if their tumor samples were scored as $2+$ on IHC, or if the samples were FISH-positive.

\section{Assessment of HER2 status by FISH}

HER2 amplification was assessed in histological samples of both PGCs and LNMs by using a Spectrum Green fluorophore-labeled $\alpha$-satellite DNA probe for chromosome 17 (CEP17) and a Spectrum Orange fluorophorelabeled DNA probe for the HER2 gene locus (VysisPath VysionHER2 DNA Probe Kit; Vysis-Abbott, Japan). Slides were hybridized using the Hybrite denaturation/ hybridization system for FISH (Vysis). Chromosome 17 polysomy was defined as $\geq 3$ CEP17 signals on average per cell. Amplification was defined as an HER2/CEP17 ratio of $\geq 2$, or when an HER2 signal cluster was observed.

\section{Statistical analysis}

Concordance between HER2 status in the primary tumor and its related metastatic sites was evaluated using Cohen's k-test, which is appropriate for assessing concordance between two categorical measurements in the same individual. A $K$-value of between 0.61 and 0.8 was assumed to indicate a very strong agreement. A $P$ value of less than 0.05 was considered to indicate statistical significance. The SAS software package for Windows, version 8.02 (SAS Institute Inc., Cary, NC, USA), and Microsoft Excel 2003 (Microsoft Co., Ltd., Japan) were used for the statistical analysis and data calculation.

\section{Results}

Patient characteristics are summarized in Table 1. The 102 patients included 82 men (80.4\%) and 20 women (19.6\%). The median age at the time of diagnosis was 68 years (ranging from 29 to 86 years). Upper gastric cancer was present in 27 patients and middle and lower gastric cancer in 75 . All patients were classified as having adenocarcinoma, intestinal type tumors. The median number of metastatic lymph nodes was 2 greater in the male group than that in the female group (4[1-100] vs. 2[1-10] respectively; $P=0.013)$. No statistically significant difference was observed in any clinical feature between males and females apart from in number of metastatic sites. The HER2 gene copy number was evaluated by IHC in 102 consecutive primary gastric adenocarcinoma specimens and their corresponding metastatic lesions and by FISH in 22. All 102 PGC and LNM specimens were adequate for IHC evaluation of HER2 status. Of the 23 PGC specimens and 23 LNM specimens selected for FISH evaluation, 
Table 1 Patient demographics and tumor characteristics

\begin{tabular}{|c|c|c|c|c|}
\hline Clinical features & $\begin{array}{c}\text { Total (\%) } \\
\mathrm{N}=102\end{array}$ & $\begin{array}{c}\text { Male (\%) } \\
\mathrm{N}=\mathbf{8 2}\end{array}$ & $\begin{array}{c}\text { Female (\%) } \\
\qquad N=20\end{array}$ & $P$ value \\
\hline Sex & & & & \\
\hline Male & $82(80.4)$ & & & \\
\hline Female & $20(19.6)$ & & & \\
\hline Age (Year) & & & & 0.348 \\
\hline Median [Range] & 68 [29-86] & 68 [29-84] & $72[29-86]$ & \\
\hline $29-49$ & $18(17.6)$ & $16(19.5)$ & $2(10.0)$ & \\
\hline $50-79$ & $73(71.6)$ & $59(57.8)$ & $14(70.0)$ & \\
\hline $79-86$ & $11(10.8)$ & $7(8.5)$ & $4(20.0)$ & \\
\hline Location & & & & 0.868 \\
\hline Upper & $27(26.5)$ & $22(26.8)$ & $5(33.3)$ & \\
\hline Middle + Lower & $75(73.5)$ & $60(73.2)$ & $15(66.6)$ & \\
\hline Operation method & & & & 0.454 \\
\hline Partial & $64(62.7)$ & $50(61.0)$ & $14(70.0)$ & \\
\hline Total & $38(37.3)$ & $32(39.0)$ & $6(30.0)$ & \\
\hline Curability & & & & 0.147 \\
\hline No residual tumors & $87(85.3)$ & $72(87.8)$ & $15(75.0)$ & \\
\hline Definite residual tumor & $15(14.7)$ & $10(12,2)$ & $5(25.0)$ & \\
\hline Clinical stage (TNM) & & & & 0.563 \\
\hline Stage I-III & $82(80.4)$ & $65(79.3)$ & $17(85.0)$ & \\
\hline Stage IV & $20(19.6)$ & $17(20.7)$ & $3(15.0)$ & \\
\hline Histological stage (TNM) & & & & 0.936 \\
\hline Stage II-III & $86(84.3)$ & $69(84.2)$ & $17(85.0)$ & \\
\hline Stage IV & $16(15.7)$ & $13(15.8)$ & $3(15.0)$ & \\
\hline \multicolumn{5}{|l|}{ Histological type } \\
\hline Intestinal & $141(100)$ & $82(100)$ & $20(100)$ & \\
\hline Diffuse & $0(0)$ & $0(0)$ & $0(0)$ & \\
\hline No of LN metastases & & & & 0.013 \\
\hline Median [Range] & 4 [1-100] & 4 [1-100] & $2[1-10]$ & \\
\hline
\end{tabular}

specimens from 1 patient were not suitable due to poor tissue fixation.

\section{Assessment of HER2 status by IHC}

HER2 expression as detected by IHC was positive or equivocal in 32 out of 102 PGC specimens (31.4\%) and 34 out of 102 LNM specimens (33.3\%). Overall, the general pattern of HER2 protein expression in each PGC was the same as in its corresponding LNMs (Table 2). HER2 amplification status was evaluable in 102 paired PGC and LNM specimens: 26 (25.5\%) were amplified and $62(60.8 \%)$ were unamplified at both sites. There were 6 discordant cases (5.9\%), where HER2 status was positive or equivocal in PGC but negative in the LNM, and 8 discordant cases (7.8\%), where HER2 status was positive or equivocal in the LNM but negative in the PGC. The results of IHC showed strong concordance in HER2 status between the PGC and LNM groups $(k=0.629)$.

\section{Assessment of HER2 status by FISH + IHC}

Of the 22 suitable PGC and LNM samples showing a result of $2+$ by IHC or a discordance in ICH results between PGC and LNM, 12 of the PGC specimens (54.5\%) showed positive HER2 expression, while 11 of the LNM samples $(50.0 \%)$ showed positive (+2) HER2 expression as detected by FISH. Of the 102 PGC samples, 27 (26.5\%) showed positive HER2 expression as detected by FISH + IHC, while 29 of 102 LNM samples (28.4\%) showed positive HER2 expression. Overall, the general pattern of HER2 protein expression in PGC as assessed by FISH + IHC was the same as in its corresponding LNM (Table 3). The HER2 amplification status was evaluable by FISH + IHC in 102 paired PGC and LNM specimens: 23 (22.5\%) were amplified and 69 (67.6\%) were unamplified at both sites. There were 4 discordant cases $(3.9 \%)$, where HER2 status was positive in the PGC but negative in the LNM (Figure 1), and 6 discordant cases (5.9\%), where HER2 status was positive in the LNM but negative in the PGC (Figure 2). The results of FISH + IHC showed very strong

Table 2 Comparison of HER2 status as assessed by IHC in 102 primary gastric carcinomas and their corresponding lymph node metastases

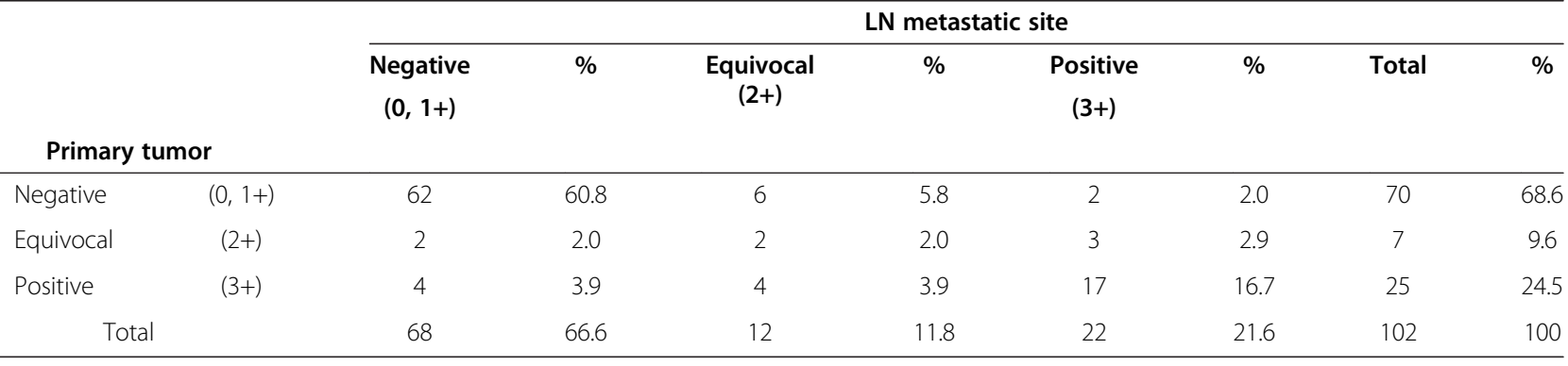


Table 3 Comparison of HER2 status as assessed by IHC and FISH in 102 primary gastric carcinomas and their corresponding lymph node metastases

\begin{tabular}{lcccccc}
\hline & \multicolumn{7}{c}{ LN metastatic site } \\
\cline { 2 - 7 } Primary tumor & Negative & $\%$ & Positive & $\%$ & Total & $\%$ \\
\hline Negative & 69 & 67.6 & 6 & 5.9 & 75 & 73.5 \\
$\quad$ Positive & 4 & 3.9 & 23 & 22.5 & 27 & 26.5 \\
Total & 73 & 71.6 & 29 & 28.4 & 102 & 100 \\
\hline$k=0.754$. & & & & & &
\end{tabular}

concordance in HER2 status between the PGC and LNM groups $(k=0.754)$.

\section{Discussion}

In the ToGA trial, the first phase III study of trastuzumab in conjunction with standard chemotherapy, HER2-positive patients with advanced gastric or gastroesophageal junction cancer were randomized to receive 5-fluorouracil/capecitabine and cisplatin, either alone or in combination with trastuzumab. Based on the results of that study, HER2-targeted molecular therapies acquired high relevance in the treatment of gastric cancer [12], indicating the importance of identifying which clinical and/or pathological features or molecular differences might be predictive of sensitivity or resistance to antiHER2 therapies.

Amplification of the HER2 gene and over-expression of its protein in gastric cancer were first described in
1986 [17], since which a number of studies have confirmed those findings [18-20]. However, how differing deregulation of HER2 between the primary gastric cancer and its metastases affects its potential as a prognostic factor remains to be clarified. Axillary lymph node metastasis is one of the most important prognostic determinants in breast carcinoma. The histopathologic characteristics and expression of biological markers vary among the same histologic subtypes of breast carcinoma. This suggests that the specific clinical and histopathologic features of the primary tumor and axillary lymph node metastases such as to a sentinel node might be used to tailor loco-regional and systemic treatment in different clinical settings in breast cancer [13-15].

Although molecular patterns may differ between a primary tumor and its associated metastases, patterns used to predict response to a given agent are usually derived from those within the primary tumor, with little attention to those found at other sites. Only a few studies have been published on this subject. Some studies assessed HER2 status in gastric cancer and confirmed a high level of concordance between HER2 status in the PGC and at various metastatic sites [20-23]. However, another study reported discordant data between HER2 status in the PGC and at various metastatic sites [24]. However, given the low number of cases analyzed and the types of cytological analysis used in these earlier studies, it is difficult to draw any conclusion with regard to HER2 status in synchronous and metachronous metastases.
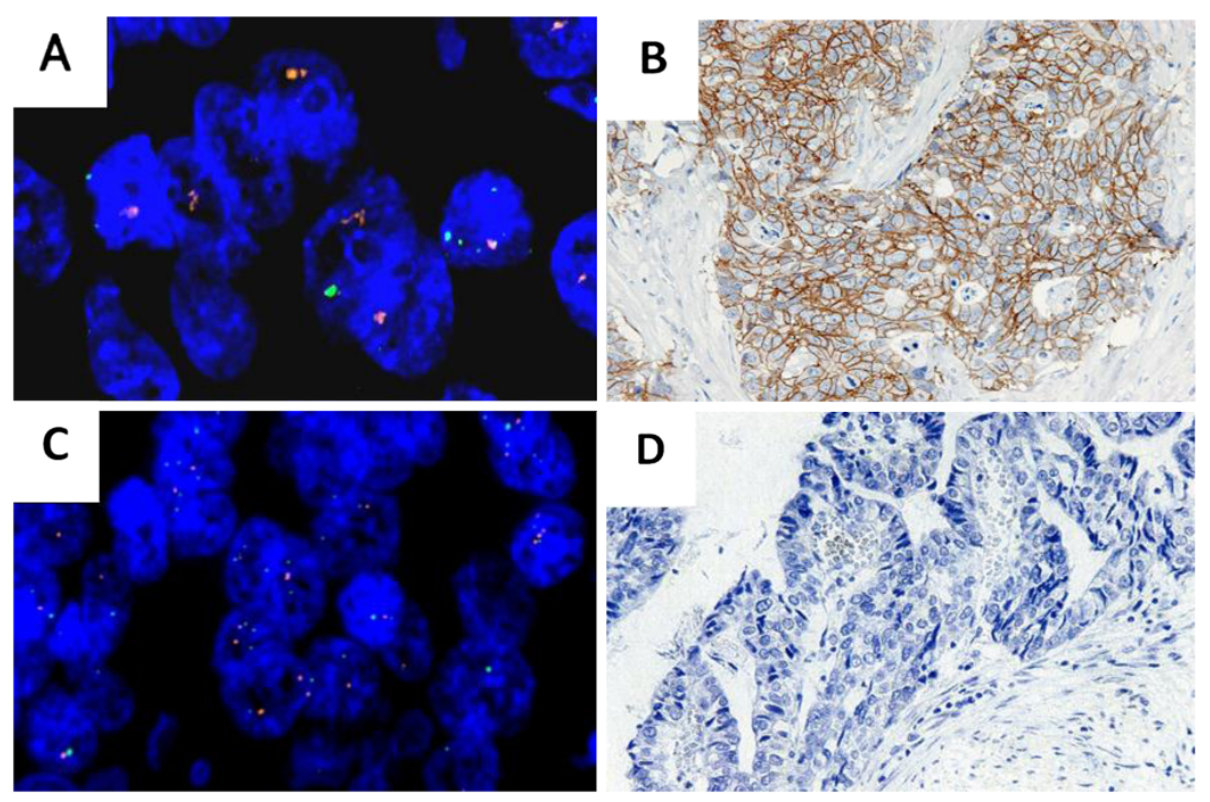

Figure 1 HER2 expression as detected by IHC and FISH in discordant cases where HER2 status was positive in the LNM but negative in the PGC. (A) FISH-positive LNM sample. (B) IHC-positive LNM sample. (C) FISH-negative PGC sample. (D) IHC-negative PGC sample. 

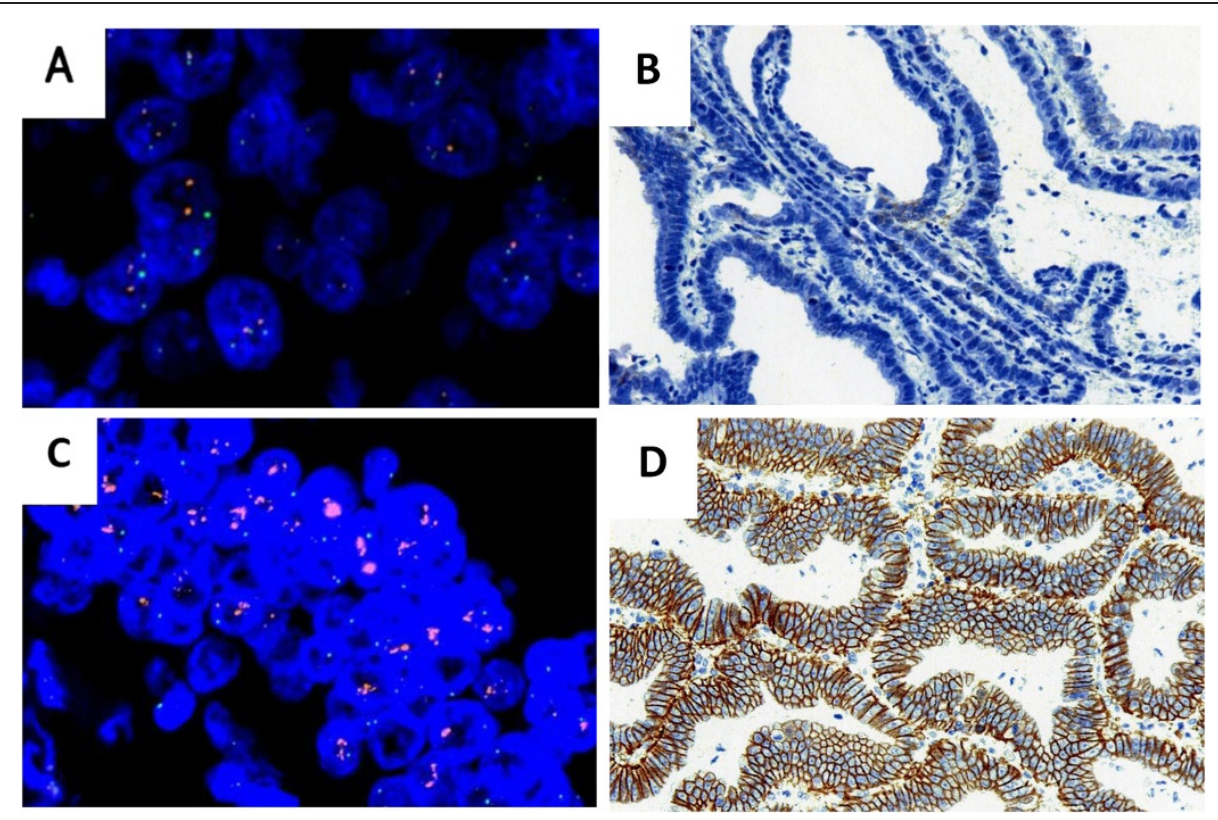

Figure 2 HER2 expression as detected by IHC and FISH in discordant cases, where HER2 status was positive in the PGC but negative in the LNM. (A) FISH-negative LNM sample. (B) IHC-negative LNM sample. (C) FISH-positive PGC sample. (D) IHC-positive PGC sample.

The concept that distant metastases may indeed show molecular patterns which differ from those in the primary tumor is supported by our current assessment of HER2 gene status by IHC and FISH. The present results showed only a moderate correlation between HER2 gene status in the PGCs and that in the LNMs. Therefore, HER2 evaluation by IHC and FISH performed only on the primary tumor may not be accurate enough to select candidates for targeted therapy. The heterogeneity of HER2 gene status in neoplastic tissues obtained from different sites in the same patient is confirmed by our findings in synchronous LNMs, with a number of patients showing a difference in HER2 gene status between the primary tumor and its distant metastasis: in 4 cases $(3.9 \%)$ the HER2 gene status was observed to be positive in the PGCs and negative in the LNMs, while in 6 cases (5.9\%), HER2 gene status was positive in the LNMs and negative in the PGCs. It is important to note, however, that concordance between the PGCs and LMNs was found in 92 of the 102 patients included in this study (90.2\%). This suggests that the treatment policy could be decided based on a sample of the PGC alone in cases where there are recurrent metastases.

Even though treatment with trastuzumab is effective, the decision to treat with trastuzumab is currently based on HER2 assessment in the PGC alone. However, the present results suggest that, as much as possible, the decision to treat with trastuzumab should be based on HER2 status as assessed in metastatic lesions.

The samples obtained in this study were obtained as far back as 1990, which means that some of them were unsuitable for application of FISH, although IHC was possible in all. To our knowledge, this is the first study including a large sample of HER2-positive patients to investigate the effect of molecular differences on the potential of HER2 status as a prognostic marker in PGCs with synchronous LNMs.

\section{Conclusion}

The results of this study indicate that HER2 status in the PGC is a reliable basis for deciding whether to treat with anti-HER2 agents in patients with LNMs. Further prospective studies are needed, however, to determine the validity of these findings. We believe that these results may be of use in clinical practice and should be taken into account in designing future clinical trials based on anti-HER2 therapy.

\section{Consent}

Written informed consent was obtained from the patients for publication of this report and any accompanying images.

\section{Competing interests}

The authors declare that they have no competing interests.

Authors' contributions

MK, MS, and TT designed the study and wrote the manuscript. SM analyzed the histological slides. YM, TF, HT, MW, and HS collected the patients' clinical information and obtained the follow-up data. All authors have read and approved the final manuscript. 


\section{Acknowledgments}

The authors wish to think all the patients and colleagues who took part in this study.

\section{Author details}

'Department of Digestive Surgery, Nihon University School of Medicine, 30-1OHyaguchi Kamimachi, Itabashi-ku, Tokyo 173-8610, Japan. ${ }^{2}$ Department of Pathology, Nihon University School of Medicine, Tokyo, Japan.

Received: 6 July 2013 Accepted: 12 November 2013

Published: 21 November 2013

\section{References}

1. Allgayer H, Babic R, Gruetzner KU, Tarabichi A, Schildberg FW: Heiss MM: c-erbB-2 is of independent prognostic relevance in gastric cancer and is associated with the expression of tumor-associated protease systems. J ClinOncol 2000, 18:2201-2209.

2. Barros-Silva JD, Leitão D, Afonso L, Vieira J, Dinis-Ribeiro M, Fragoso M, Bento MJ, Santos L, Ferreira P, Rêgo S, Brandão C, Carneiro F, Lopes C, Schmitt F, Teixeira MR: Association of ERBB2 gene status with histopathological parameters and disease-specific survival in gastric carcinoma patients. $\mathrm{Br} J$ Cancer 2009, 100:487-493.

3. Jørgensen JT: Targeted HER2 treatment in advanced gastric cancer. Oncology 2010, 78:26-33.

4. Lee HR, Kim JH, Uhm HD, Ahn JB, Rha SY, Cho JY, Lee Jl, Lee KH, Chung HC, Roh JK, Min JS, Lee KS, Shin DH, Kim BS, Hong SW, Choi JH: Overexpression of c-ErbB-2 protein in gastric cancer by immunohistochemical stain. Oncology 1996, 53:192-197.

5. Lee KE, Lee HJ, Kim YH, Yu HJ, Yang HK, Kim WH, Lee KU, Choe KJ, Kim JP: Prognostic significance of p53, nm23, PCNA and c-erbB-2 in gastric cancer. Jpn J ClinOncol 2003, 33:173-179.

6. Ooi A, Kobayashi M, Mai M, Nakanishi I: Amplification of c-erbB-2 in gastric cancer: detection in formalin-fixed, paraffin-embedded tissue by fluorescence in situ hybridization. Lab Invest 1998, 78:345-358.

7. Yano T, Doi T, Ohtsu A, Boku N, Hashizume K, Nakanishi M, Ochiai A: Comparison of HER2 gene amplification assessed by fluorescence in situ hybridization and HER2 protein expression assessed by immunohistochemistry in gastric cancer. Oncol Rep 2006, 15:65-71.

8. Yu GZ, Chen Y, Wang JJ: Overexpression of Grb2/HER2 signaling in Chinese gastric cancer: their relationship with clinicopathological parameters and prognostic significance. J Cancer Res ClinOncol 2009, 135:1331-1339.

9. Shan L, Ying J, Lu N: HER2 expression and relevant clinicopathological features in gastric and gastroesophageal junction adenocarcinoma in a Chinese population. Diagn Pathol 2013, 9:76.

10. Laurinaviciene A, Dasevicius D, Ostapenko V, Jarmalaite S, Lazutka J: Laurinavicius: a $A B C G 2$ is associated with HER-2 expression, lymph node metastasis and clinical stage in breast invasive ductal carcinoma. Diagn Pathol 2011, 23:87.

11. Vogel UF: Confirmation of a low HER2 positivity rate of breast carcinomas - limitations of immunohistochemistry and in situ hybridization. Diagn Pathol 2010, 29:50.

12. Bang YJ, Van Cutsem E, Feyereislova A, Chung HC, Shen L, Sawaki A, Lordick F, Ohtsu A, Omuro Y, Satoh T, Aprile G, Kulikov E, Hill J, Lehle M, Rüschoff J, Kang YK: ToGA Trial Investigators: Trastuzumab in combination with chemotherapy versus chemotherapy alone for treatment of HER2positive advanced gastric or gastro-oesophageal junction cancer (ToGA): a phase 3, open-label, randomised controlled trial. Lancet 2010, 376:687-697.

13. Yenidunya S, Bayrak R, Haltas $H$ : Predictive value of pathological and immunohistochemical parameters for axillary lymph node metastasis in breast carcinoma. Diagn Pathol 2011, 13:18

14. Xiang L, Su P, Xia S, Liu Z, Wang Y, Gao P, Zhou G: ABCG2 is associated with HER-2 expression, lymph node metastasis and clinical stage in breast invasive ductal carcinoma. Diagn Pathol 2011, 27:90.

15. Simon R, Nocito A, Hübscher T, Bucher C, Torhorst J, Schraml P, Bubendorf L, Mihatsch MM, Moch H, Wilber K, Schötzau A, Kononen J, Sauter G: Patterns of her-2/neu amplification and overexpression in primary and metastatic breast cancer. J Natl Cancer Inst 2001, 93:1141-1146.

16. Hofmann M, Stoss $O$, Shi D, Büttner R, van de Vijver M, Kim W, Ochiai A, Rüschoff J, Henkel T: Assessment of a HER2 scoring system for gastric cancer: results from a validation study. Histopathology 2008, 52:797-805.
17. Fukushige S, Matsubara K, Yoshida M, Sasaki M, Suzuki T, Semba K, Toyoshima K, Yamamoto T: Localization of a novel v-erbB-related gene, c-erbB-2, on human chromosome 17 and its amplification in a gastric cancer cell line. Mol Cell Biol 1986, 6:955-958.

18. Sakai K, Mori S, Kawamoto T, Taniguchi S, Kobori O, Morioka Y, Kuroki T, Kano K: Expression of epidermal growth factor receptors on normal human gastric epithelia and gastric carcinomas. J Natl Cancer Inst 1986, 77:1047-1052.

19. Yonemura Y, Ninomiya I, Yamaguchi A, Fushida S, Kimura H, Ohoyama S, Miyazaki I, Endou Y, Tanaka M, Sasaki T: Evaluation of immunoreactivity for erbB-2 protein as a marker of poor short term prognosis in gastric ancer. Cancer Res 1991, 51:1034-1038.

20. Yonemura Y, Ninomiya I, Ohoyama S, Fushida S, Kimura H, Tsugawa K, Kamata T, Yamaguchi A, Miyazaki I, Endou Y: Correlation of c-erbB-2 protein expression and lymph node status in early gastric cancer. Oncology 1992, 49:363-367.

21. Bozzetti C, Negri FV, Lagrasta CA, Crafa P, Bassano C, Tamagnini I, Gardini G, Nizzoli R, Leonardi F, Gasparro D, Camisa R, Cavalli S, Silini EM, Ardizzoni A: Comparison of HER2 status in primary and paired metastatic sites of gastric carcinoma. Br J Cancer 2011, 26:1372-6.

22. Marx AH, Tharun L, Muth J, Dancau AM, Simon R, Yekebas E, Kaifi JT, Mirlacher M, Brümmendorf TH, Bokemeyer C, Izbicki JR, Sauter G: HER-2 amplification is highly homogenous in gastric cancer. Hum Pathol 2009, 40:769-777.

23. Kim MA, Lee HJ, Yang HK, Bang YJ, Kim WH: Heterogeneous amplification of ERBB2 in primary lesions is responsible for the discordant ERBB2 status of primary and metastatic lesions in gastric carcinoma. Histopathology 2011, 59:822-831.

24. Kim JH, Kim MA, Lee HS, Kim WH: Comparative analysis of protein expressions in primary and metastatic gastric carcinomas. Hum Pathol 2009, 40:314-322.

doi:10.1186/1746-1596-8-191

Cite this article as: Kochi et al:: Differing deregulation of HER2 in primary gastric cancer and synchronous related metastatic lymph nodes. Diagnostic Pathology 2013 8:191.

\section{Submit your next manuscript to BioMed Central and take full advantage of:}

- Convenient online submission

- Thorough peer review

- No space constraints or color figure charges

- Immediate publication on acceptance

- Inclusion in PubMed, CAS, Scopus and Google Scholar

- Research which is freely available for redistribution

Submit your manuscript at www.biomedcentral.com/submit
C Biomed Central 